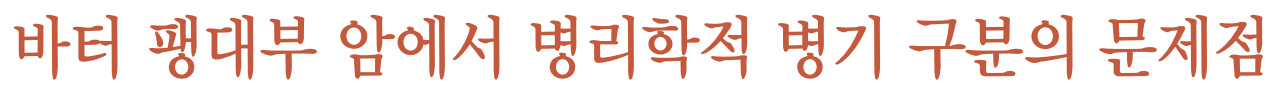

성균관대학교 의과대학 삼성서울병원 병리과

장 기 택

\title{
Problems of Pathologic T Staging in Ampullary Neoplasm
}

\author{
Kee-Taek Jang \\ Department of Pathology, Samsung Medical Center, Sungkyunkwan University School of Medicine, Seoul, Korea
}

Ampulla of Vater (AoV) is a small dilated duct less than $1.5 \mathrm{~cm}$ long, formed by the union of pancreatic duct and common bile duct. AoV has also anatomic layer of mucosa, sphincter of Oddi, perisphincteric or duodenal submucosa, and duodenal proper muscle, which corresponds to mucosa, muscularis mucosa, submucosa, and proper muscle layer of other gastrointestinal tract organs, respectively. Because of its small compact size and variation of anatomic structure, it is sometimes difficult to identify layering architecture of AoV. This anatomic difficulty may cause some problem in T classification of ampullary carcinoma (AC). The most confusing point in T classification is the vague definition of T2, "Tumor invades duodenal wall". It seems that duodenal wall includes duodenal mucosa, submucosa, and proper muscle layer. However there is no precise description or definition about duodenal wall that might lead personal variation in T classification of AC staging. We found that clinical course of AC with perisphincteric and/or duodenal submucosal invasion is more close to AC with T2 than T1. Although it is described as T1b according to $T$ classification scheme of ordinary gastrointestinal tract cancer, we thought $A C$ with T1b may have more high-grade malignant potential than those of other gastrointestinal (Gl) tract malignancy. AC showed various clinicopatholgic findings that represent heterogeneous tumor groups within category of AC. Recently sitespecific classification of AC was introduced, and it showed relatively well-categorized clinical prognosis. It may be reasonable to understand site-specific tumorigenesis in AC. The standard gross protocol is needed to evaluate pathologic T classification of AC. In conclusion, ampullary neoplasm is composed of various subtypes, which require a separate approach according to anatomic epicenter of ampullary neoplasm. Although submucosal invasion in AC was classified into pT1b, its' biologic behavior is more close to $\mathrm{pT} 2$.

Korean J Pancreas Biliary Tract 2014;19(3):117-120

Keywords: Ampulla of vater, Neoplasm Staging, Duodenum
Received Jun. 3,2014
Revised Jun. 22, 2014
Accepted Jun. 25, 2014

Corresponding author : Kee-Taek Jang

Department of Pathology, Samsung Medica Center, 80 Irwon-ro, Gangnam gu, Seoul 135-710, Korea

Tel. +82-2-3410-2763 Fax. +82-2-3410-0025

E-mail; kt12.jang@samsung.com

This is an Open Access article distributed under the terms of the Creative Commons Attribution Non-Commercial License (http: creativecommons.org/licenses/by-nc/3.0/) which permits unrestricted non-commercial use, distribution, and reproduction in any medium, provided the original work is properly cited.

\section{서 론}

바터 팽대부(ampulla of vater)는 작은 크기에도 불구하고
복잡한 해부학적 구조로 이루어져 있으며 십이지장 점막과 췌관, 총담관의 윈위부가 모여서 형성된다. ${ }^{1}$ 바터 팽대부는 다른 소화기 장관의 해부학적 층 구조와 마찬가지로 점막층, 


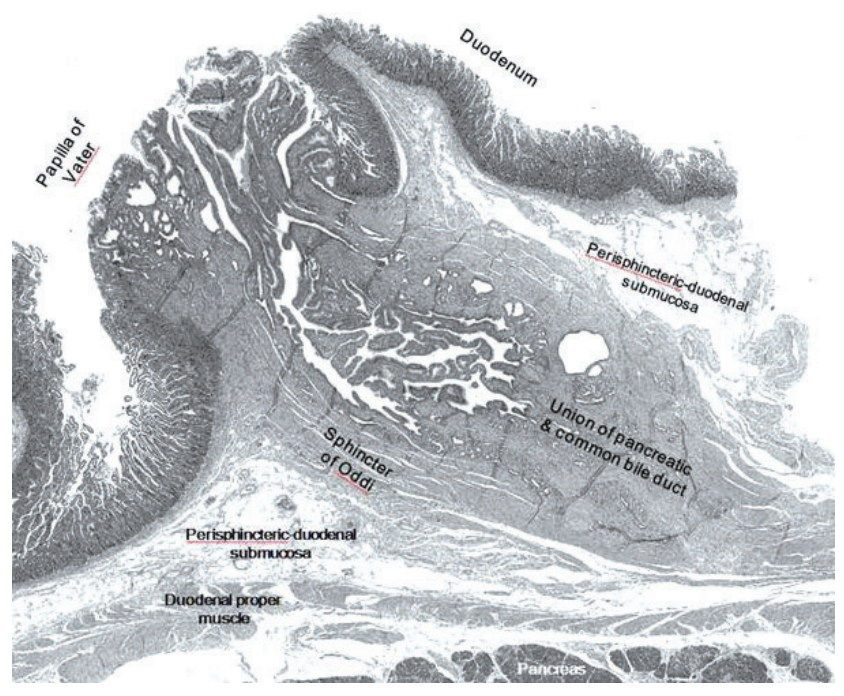

Fig. 1. Normal anatomy and histology of ampulla of vater.

오디 조임근(sphincter of oddi), 오디 조임근 주변 점막하층, 십이지장 근육층으로 구성되어 있다. 하지만 다른 소화기 기 관에서는 해부학적 층 구조가 비교적 명확하게 구분되지만 바터 팽대부에서는 이런 층 구조의 구분이 명확하지 않다. 정상 바터 팽대부에서는 점막층은 주로 십이지장의 점막층 으로 구성되고 바터 유두(papilla of vater)에서 췌관과 총담 관의 윈위부와 만난다. 대개의 경우 원위부 췌관과 총담관은 바터 팽대부에서 만나서 하나의 통로를 형성하여 십이지장 점막과 연결되고 오디 조임근은 이 통로 주변을 둘러싸면서 아래로 내려가 십이지장 근육층과 합져진다(Fig. 1). 하지만 바터 팽대부에서 종양이 생기거나 염증이 심한 경우 오디 조 임근이 비대해지면서 층간 구분이 어려워지고 특히 십이지 장 근육층과의 구분이 어려운 경우가 많다. 현재 사용되는 바터 팽대부암에 대한 병기 판정기준은 미국 암병기 위원회 의 2010년 7판(American Joint Committee of Cancer Staging, 7th edition, 2010)이며 바터 팽대부암의 종양 침윤에 따 른 병기 기준은 표 1 에 정리하였다. 다른 소화기 기관에서의 병기 판정에서는 점막층에 국한된 경우나 점막하층까지 침 범한 경우(T1), 근육층을 침범한 경우(T2), 근육층을 넘어선 경우(T3) 등을 구분하는데 이를 바터 팽대부 종양에 맞추어 구분할 경우 바터 팽대부에 국한된 경우(T1), 십이지장 벽을 침범한 경우(T2), 췌장을 침범한 경우(T3) 등으로 구분하고 있다(Table 1).
Table 1. Current Pathologic T classification of Ampullary Carcinoma (American Joint Committee of Cancer Staging, 7th edition, 2010)

\begin{tabular}{ll}
\hline Tis & Carcinoma in situ \\
\hline T1 & Tumor limited to ampulla of vater or sphincter of Oddi \\
T2 & Tumor invades duodenal wall \\
T3 & Tumor invades pancreas \\
T4 & $\begin{array}{l}\text { Tumor invades peripancreatic soft tissue or other adjacent } \\
\text { organs or structures other than pancreas }\end{array}$ \\
\hline
\end{tabular}

\section{본 론}

\section{1. 바터 팽대부암 병기 판정에서 $\mathrm{T} 1, \mathrm{~T} 2$ 구분의 문제점}

병리 진단에서 다른 소화기 기관 종양과 달리 바터 팽대부 는 T1, T2 의 구분이 분명치 않은 경우를 어렵지 않게 경험할 수 있다. 현재 미국 암병기위원회의 지침에 따르면 $\mathrm{T} 1$ 은 바 터 팽대부나 오디 조임근에 국한된 경우로 정의하고 있고 $\mathrm{T} 2$ 는 십이지장 벽을 침범한 경우로 정의하고 있다. 하지만 이 러한 구분은 실제 병기 진단에서 많은 문제점을 안고 있다. 이러한 문제점의 결과를 가장 잘 보여주는 것은 현재 사용 중인 2010년 7판 암병기 책자에서 팽대부 암의 생존율 곡선 자료에서 $\mathrm{T} 2$ 가 $\mathrm{T} 1$ 보다 생존율 분석에서 더 나은 것으로 보 여진다는 점이다. 이러한 현상은 현재 팽대부 암종의 병기 판정에 문제가 있음을 시사하는 것이며 $\mathrm{T} 1$ 과 $\mathrm{T} 2$ 간의 구분 이 명확하지 않거나 실제로는 T2에 해당하는 증례들이 $\mathrm{T} 1$ 에 포함되어 있기 때문일 것으로 추정된다. 구체적으로 $\mathrm{T} 1$ 에 대 한 기술에서 오디 조임근에 국한된 종양이란 표현과 함께 바 터 팽대부에 국한된 종양을 $\mathrm{T} 1$ 으로 기술한 것이 문제점인 것 으로 보인다. 바터 팽대부는 작지만 문제점으로 여러 구조가 모여서 형성한 기관이기 때문에 바터 팽대부에 국한된 종양 이란 표현은 바터 팽대부를 어떻게 정의하느냐에 따라서 상 당히 주관적인 해석이 가능하다는 문제점이 있다. 또한 T2 정의에서 십이지장 벽을 침범한 것으로 기술되어 있는데 십 이지장 벽이 구체적으로 어떤 구조를 지칭하는 것인지에 대 한 설명이 빠져 있어 해석에 많은 문제점이 있다. 통상적으 로 소화기 장관에서 벽을 침범한다는 것은 근육층을 침범하 는 것을 지칭하기 때문에 십이지장 근육층을 침범한 것으로 해석할 수 있지만 바터 팽대부에서 종양이 생긴 경우 오디 조임근이 비대해지면서 십이지장 근육층과 합쳐지는 지점 에서의 구분이 명확하지 않은 경우가 많다. 실제 십이지장 근육층을 침범하지 않고 비대해진 오디 조임근을 침범한 증 
례를 T2로 판정되었을 경우 현재 암병기 책자에서 보여주는 $\mathrm{T} 1$ 과 $\mathrm{T} 2$ 간의 생존율 곡선의 역전 현상을 보일 가능성이 높 다. 따라서 보다 정확하고 객관적인 T2 종양을 구별하기 위 해서는 내원형, 외세로층의 두개의 구조로 확인되는 근육층 을 침범한 것으로 정의하는 것이 타당할 것으로 보인다. 그 리고 바터 팽대부암이 오디 근육층을 넘어서서 십이지장 점 막하층까지 침범할 경우 어떤 $\mathrm{T}$ 병기가 적합한지 명확한 기 준이 없다. 현재 사용되는 7판 암병기 기준에 따르면 바터 팽 대부에 국한된 종양이란 기술에 따라서는 T1으로 분류될 수 도 있지만 오디 조임근을 넘어섰다는 점에서 $\mathrm{T} 1$ 보다는 $\mathrm{T} 2$ 에 가깝다고 해석될 수 있다. 하지만 이는 현재 $\mathrm{T} 2$ 의 정의가 십 이지장 벽, 즉 근육층을 침범한 경우로 정의되어 있어 $\mathrm{T} 2$ 로 분류되는데도 문제점이 있다. 기존의 위, 대장 등의 다른 소 화기 장관에 준용해서 해석한다면 점막하층 침범은 $\mathrm{T} 1 \mathrm{~b}$ 에 해당할 것이다. 하지만 최근 105 증례의 $\mathrm{T} 1, \mathrm{~T} 2$ 조기 바터 팽 대부암을 분석한 연구에서 오디 근육층 주변-십이지장 점막 하층을 침범한 바터 팽대부암은 T1보다 T2에 가까운 임상 경과를 보여준다는 것이 보고되었다. ${ }^{2}$ 따라서 $\mathrm{T} 2 \mathrm{a}$ 로도 해석 이 가능하겠지만 다른 소화기 장관에서의 $\mathrm{T}$ 병기 원칙을 따 른다는 점에서 $\mathrm{Tlb}$ 로 구분하는 것이 정리되었다. 하지만 다 른 소화기 장기에서의 $\mathrm{T} 1 \mathrm{~b}$ 보다는 $\mathrm{T} 2$ 에 가까운 임상 경과를 보였다는 점에서 바터 팽대부에서 생기는 $\mathrm{T} 1 \mathrm{~b}$ 의 종양은 다 른 소화기 장기에서의 $\mathrm{Tlb}$ 보다 악성도가 높은 것으로 보인 다. 이것은 바터 팽대부의 해부학적 구조적 원인이 큰 영향 을 미치기 때문인 것으로 추정된다. 다른 소화기 장기에서 점막하층은 점막 근육층과 본 근육층(proper muscle layer) 사이에 비교적 넓은 공간을 차치하는데 비해 바터 팽대부에 서는 오디 조임근 너머-십이지장 점막하층은 대단히 좁은 공 간을 차지하고 인접한 십이지장 본 근육층이나 췌장 등과도 상당히 가깝다. 따라서 비슷한 정도의 침범이라고 하더라도 다른 소화기 장기에서는 점막하 침범보다 바터 팽대부 암종 에서의 점막하 침범이 휠씬 더 높은 악성도를 보이는 것으로 추정되며 오디 조임근 너머-십이지장 점막하층 침범이 있는 경우 림프절 전이나 사망률이 상대적으로 높은 것도 이를 뒷 받침하는 소견이라고 볼 수 있다.

\section{2. 바터 팽대부암 병기 판정에서 $\mathrm{T} 3, \mathrm{~T} 4$ 구분의 문제점}

바터 팽대부암 병기 판정에서는 T1, T2 구분뿐만 아니라 $\mathrm{T} 3, \mathrm{~T} 4$ 구분에서도 많은 문제점을 보여주고 있다. 현재 2010 년 7판 미국암병기 기준에서는 췌장을 침범한 경우 $\mathrm{T} 3$, 췌장
을 넘어선 지방조직까지 침범할 경우 $\mathrm{T} 4$ 로 규정하고 있다. 이러한 구분은 기존의 다른 소화기 장기 구분과 형평성을 맞 추어서 작성한 것으로 보이지만 문제점은 $\mathrm{T} 3$ 로 구분되는 췌 장은 바터 팽대부 전체를 둘러싸고 있지 않다는 점이다. 구 체적으로 바터 팽대부는 췌장과 십이지장으로 둘러싸여 있 으며 통상적인 병리학적 육안 검사에서 많이 사용되는 수직 절단면에서 췌장과 십이지장 벽 사이에 삼각형 형태의 부위 가 관찰되며 일부 바터 팽대부암이 이 부위를 통해서 십이지 장 너머로 퍼지기도 한다. 따라서 $\mathrm{T} 3$ 를 췌장 침범으로만 국 한할 경우 위와 같은 침범 양상을 보이는 종양은 병기 판정 에 있어서 모호하거나 저평가될 가능성이 높다. 따라서 십이 지장 본 근육층을 넘어선 침범은 췌장 침범과 동일한 $\mathrm{T} 3$ 로 구분하는 것이 타당하다.

\section{3. 부위별 바터 팽대부암의 구분(Site specific classi- fication)}

바터 팽대부는 작은 크기에도 불구하고 여러 가지 기관이 모여서 형성된 기관이다. 따라서 이들 각 기관 세포에서 종 양이 생길 경우 다양한 임상병리학적 소견을 보이게 된다. 소화기 내과쪽에서 흔하게 보는 것은 십이지장과 인접한 파 터 팽대부의 점막층에서 기원한 종양이며 대장에서 흔히 관 찰되는 선종(adenoma)과 유사한 배경 병변을 가지는 경우 가 많다. 소화기 내과에서 유두절제술(papillectomy)을 통해 치료되는 바터 팽대부 병변은 대부분 이와 같은 선종 배경을 가진 팽대부 주변-십이지장으로 구분되는 종양에 속한다..$^{3-6}$ 일부 바터 팽대부 종양은 바터 팽대부 내강에서 유두상 종괴 를 형성하면서 자라는 경우가 있는데 이때 바터 팽대부의 표 면 점막은 정상 소견을 보이면서 결절성의 점막하 종괴 형태 로 관찰된다. 바터 팽대부 내강을 채우는 유두상 종괴로 관 찰되고 주변 조직으로 침윤이 없는 경우 내시경 유두절제술 로도 치료가 가능하다는 보고도 있다. ${ }^{7}$ 병리조직학적 검사에 서 이러한 점막하 종괴는 유두상 구조를 보이는 경우가 많은 데 췌장에서 관찰되는 관내 유두-점액성 종양(intraductal papillary-mucinous neoplasm)과 조직학적 양상이 유사하고 종괴를 형성하는 전암성 병변이란 점에서 팽대부내 유두관 상 종양(intra-ampullary papillary-tubular neoplasm)으로 보고된 문헌도 있다. ${ }^{8}$ 일부 종양은 팽대부 주변 십이지장 점 막과 바터 팽대부내 유두상 종괴 사이 지점인 바터 유두(papillae vater)에서 기원하는데 이 경우 종괴의 중심점은 파터 유두에 해당하는 점으로 감별할 수 있다. 바터 팽대부의 해 
부학적 구조에서 가장 안쪽(근위부)에 해당하는 췌관 또는 총담관의 말단부위 세포에서 기원한 경우 종양은 통상적인 윈위부 담관암이나 췌장암의 임상 경과를 따르는 경우가 많 아 다른 부위에서 생기는 암종에 비해서 예후가 좋지 않은 것 으로 알려졌다. 이와 같이 바터 팽대부암은 하나의 단일 암종 이라기보다는 여러 해부학적 구조 기원의 다양한 암종이 모 여있는 것으로 해석하는 것이 타당할 것으로 보인다. Adsay 등 $^{9,10}$ 은 이와 같은 소견을 바탕으로 바터 팽대부암을 부위별 로 구분하여 병기 진단할 것을 제안하였다.

\section{결 론}

바터 팽대부 암종은 해부학적으로 여러 기관이 모여서 형 성된 기관으로 구조적 복잡성으로 인해 병리학적 병기 판정 에 어려움이 많고 현재 사용되는 병기 판정은 환자의 임상경 과나 예후를 제대로 반영하지 못하는 것으로 보인다. 따라서 새로운 병기 판정에 있어서 해부학적 위치와 병리 조직학적 소견을 바탕으로 종괴 중심점과 기원세포의 유형에 따라 구 분하는 것이 타당해 보이며 이를 바탕으로 개선된 병기 판정 기준에 대한 많은 확인 연구가 필요하다. 또한 정확한 병기 판정을 위해서는 일관성 있는 병리 육안검사와 보고서 작성 이 필수적이다.

국문 색인: 바터 팽대부 암종, 병기, 부위별 구분

\section{Conflicts of Interest}

The author has no conflicts to disclose.

\section{REFERENCES}

1. Edge SB, Byrd DR, Compton CC, Fritz AG, Greene FL, Trotti A. AJCC Cancer Staging Manual. 7th ed. New York, Springer, 2010

2. Dong Do You, Jin Seok Heo, Seong Ho Choi, et al. How do we classify perisphincteric or duodenal submucosal invasion in t classification of amullary carcinoma. Arch Pathol Lab Med 2014 (in press).

3. Nguyen N, Shah JN, Binmoeller KF. Outcomes of endoscopic papillectomy in elderly patients with ampullary adenoma or early carcinoma. Endoscopy 2010;42:975-977.

4. Cheng CL, Sherman S, Fogel EL, et al. Endoscopic snare papillectomy for tumors of the duodenal papillae. Gastrointest Endosc 2004;60:757764.

5. Napoleon B, Gincul R, Ponchon T, et al. Endoscopic papillectomy for early ampullary tumors: long-term results from a large multicenter prospective study. Endoscopy 2014;46:127-134.

6. Jung MK, Cho CM, Park SY, et al. Endoscopic resection of ampullary neoplasms: a single-center experience. Surg Endosc 2009;23:25682574.

7. Bohnacker $S$, Seitz $U$, Nguyen $D$, et al. Endoscopic resection of benign tumors of the duodenal papilla without and with intraductal growth. Gastrointest Endosc 2005:62:551-560.

8. Ohike N, Kim GE, Tajiri T, et al. Intra-ampullary papillary-tubular neoplasm (IAPN): Characterization of tumoral intraepithelial neoplasia occurring within the ampulla: a clinicopathologic analysis of 82 cases. Am J Surg Pathol 2010;34:1731-1748.

9. Adsay VN, Ohike N, Tajiri T, et al. Ampullary region carcinomas; definition and site specific classification with delineation of four clinicopathologically and prognostically distinct subsets in an analysis of 249 cases. Am J Surg Pathol 2012;36:1592-1608.

10. Adsay NV, Bagci P, Tajiri T, et al. Pathologic staging of pancreatic, ampullary, biliary, and gallbladder cancers: pitfalls and practical limitations of the current AJCC/UICC TNM staging system and opportunities for improvement. Semin Diagn Pathol 2012;29:127-141. 